\title{
Importância dos aditivos na alimentação de cães e gatos: Revisão
}

\author{
$\underline{\text { Sandro Cappelli }}^{*}{ }^{*}, \underline{\text { Emanuel Manica }}^{1}$, Juliano Hideo Hashimoto $^{2}$ \\ IZootecnista Formado pelo IFRS - Campus Sertão; Sertão - RS, Brasil \\ ${ }^{2}$ Doutor em Zootecnia pela Universidade Federal de Pelotas. Professor Docente do Curso de Zootecnia do IFRS \\ - Campus Sertão; Sertão - RS, Brasil \\ *Autor para correspondência, e-mail: sandro.cappelli@hotmail.com
}

\begin{abstract}
RESUMO. Os aditivos nas rações de cães e gatos passaram a ter grande importância no mercado de pet foods. Isto devido ao papel que os animais de estimação passaram a ocupar nos últimos anos, aproximando-se cada vez mais das pessoas e tornando-se dependentes dos seres humanos. O objetivo do estudo bibliográfico tem por finalidade destacar a importância dos aditivos, principalmente nas rações secas extrusadas, tratando das particularidades de ambas as espécies. Os aditivos tem a função de atender as exigências nutricionais que as matérias primas empregadas na fabricação das rações não fornecem. Além disso, existem aditivos que são capazes de gerar benefícios, tais como: aprimorar a digestibilidade; melhorar a qualidade das fezes e da microbiota intestinal; amenizar quadros clínicos que os animais podem sofrer, como problemas dermatológicos, intestinais e das articulações. Quando adicionados a alimentação de cães e gatos promovem benefícios ao animal a curto e longo prazo, aprimorando a saúde do pet.
\end{abstract}

Palavras chave: Pet food, rações extrusadas, nutrição, saúde, animais pet.

\section{Importance of additives in feeding dogs and cats: Review}

\begin{abstract}
Additives in pet feed started to have big importance in the market. This due to the part of the pets passed to have in the last years, approaching more and more of the people e becoming dependents of human beings. The main of this study have the purpose to show the importance of the additives, principally in the extruded feed, addressing the particularities of both species. They function is to attempt the nutritional requirements that the feedstock used in the fabrication of pet feed don't supply. Furthermore, there are additives that are able to generate benefits, like: improving the digestibility; the faeces quality and the intestinal microbiota; ease medical conditions that animals can suffer, as skin, intestinal and articulations problems. They can provide benefits to animals in a short or a long time, improving health to pet when they are add in their feed.
\end{abstract}

Key words: Pet food, extruded feed, nutrition, health, pet.

\section{Introdução}

Com o passar dos anos, os animais de estimação ganharam outro espaço dentro da sociedade, saindo dos pátios e em muitos casos passando para dentro das residências, fazendo parte do convívio familiar. Vários motivos fizeram com que ocorresse essa mudança, tornando estes animais cada vez mais próximos dos seres humanos. Dentre os animais de estimação, os que mais se destacam são os cães e os gatos, por proporcionarem maior interação com seus donos.
O número de animais de estimação, principalmente cães e gatos é bastante expressivo. De acordo com a ABINPET (2013) no Brasil existem cerca de 37,1 milhões de cães e 23,1 milhões de gatos, tonando o país a quarta maior nação em população de animais de estimação.

O acentuado número de animais de estimação é o responsável por alavancar o comércio do segmento pet. De acordo com a ABINPET (2013) o setor movimentou cerca de $\mathrm{R} \$ 15,2$ bilhões, sendo a maior fatia representada pelos 
produtos Pet Foods, representando cerca de 66\% do faturamento total do setor.

Dentro deste mercado, as rações secas são as que mais se destacam, devido a ser a forma mais fácil de nutrir o animal, não necessitando de preparo, apenas o fornecimento e atendendo todas as exigências nutricionais para a manutenção da vida do animal em suas diferentes fases.

Com a migração para dentro das residências, a indústria passou a fabricar rações com uma composição baseada nas necessidades específicas de cada animal, obtidas através dos aditivos que são adicionados na industrialização das rações, com a finalidade de atender as necessidades nutricionais dos animais. Outros componentes podem ser adicionados com a intenção de melhorar a saúde dos animais, conservar a ração, melhorar a aparência, palatabilidade e exercer função terapêutica e funcional.

O estudo visa buscar na bibliografia novos aditivos utilizados na fabricação das rações, destacando as funcionalidade, particularidades e as diferenças entre a necessidade de cães e gatos, ressaltando os benefícios gerados para ambas as espécies.

\section{Regulamentação e função dos aditivos}

Segundo IN 30/2009 do MAPA, consideramse aditivos: substâncias, microrganismos ou produtos formulados e adicionados intencionalmente aos alimentos, que não são utilizados normalmente como ingredientes, tenham ou não valor nutritivo e que melhorem as características dos produtos destinados à alimentação animal, melhorando o desempenho dos animais sadios e atendendo às necessidades nutricionais.

Os aditivos têm por finalidade preservar as características nutricionais das rações, facilitando a dispersão dos ingredientes e aprimorando o crescimento dos animais (Souza \& Silva, 2008). Devendo ao mesmo tempo ser incluídos em uma das seguintes categorias: tecnológicos, sensoriais, nutricionais, zootécnicos ou anticoccidianos (MAPA, 2004)

\section{Alimentos nutracêuticos e funcionais}

As rações comerciais para animais de estimação são formuladas para atender todas as necessidades específicas de nutrientes em diferentes estados fisiológicos de cães e gatos. O valor nutricional da ração para a manutenção da vida do animal deve estar de acordo com a Association of American Feed Control Officilas, pois é o órgão que determina as quantidades mínimas e máximas de nutrientes para os diferentes estados fisiológicos dos cães e gatos (França et al., 2011).

Os alimentos funcionais devem apresentar propriedades benéficas além das nutricionais básicas, são alimentos da composição normal da dieta, mas que demonstram capacidade de regular as funções corporais, auxiliando o organismo na proteção contra doenças, tais como: hipertensão, diabetes, câncer, osteoporose e coronariopatias (Souza et al., 2003).

Todos os ingredientes funcionais encaixam-se dentro de um grupo de compostos que apresentam benefícios à saúde, tais como: as alicinas presentes no alho; os carotenoides e flavonoides presentes em frutas e vegetais; os glucosinolatos encontrado nos vegetais crucíferos e os ácidos graxos poliinsaturados presentes em olhos de peixes ou vegetais (Kruger \& Mann, 2003).

Nutracêutico é considerado um alimento ou parte dele que proporciona benefícios a saúde, atuando na prevenção e no tratamento de doenças. Compõe uma ampla variedade de alimentos e componentes alimentícios importantes para o funcionamento do organismo (Hungenholtz \& Smid, 2002).

As funções de ambos os alimentos são diferentes, pois os nutracêuticos dizem respeito à prevenção e o tratamento de doenças e os funcionais estão envolvidos na redução dos riscos das doenças.

Devido aos benefícios gerados pelos alimentos funcionais e nutracêuticos na vida dos animais, proporcionando maior longevidade, manutenção da saúde e prevenção de doenças, faz com que as indústrias comecem a apostar cada vez mais em rações que trabalhem para a melhoria da qualidade de vida do Pet.

\section{Taurina}

A taurina é um ácido beta-amino-sulfônico único, que não faz parte das proteínas, mas que se encontra como aminoácido livre nos tecidos. É um aminoácido sintetizado pela maioria dos mamíferos a partir da metionina e cistina (Case et al., 1998). 
Os gatos diferente de outras espécies necessitam de maiores quantidades de taurina, sendo importante para diferentes funções no organismo, exercendo papel sobre: visão; audição; reprodução; crescimento; emulsificação de gorduras e conjugação de ácidos biliares; atuam na musculatura esquelética; preservação das funções cardiovasculares e sobre as respostas do sistema imune dos animais (Hora \& Hagiwara, 2010).

A suplementação nas rações enlatadas devem ser superiores as rações secas, pois ocorrem perdas de taurina devido ao incremento da circulação enterohepática e da degradação bacteriana do ácido taurocólico no intestino (Case et al., 1998). A taurina é altamente solúvel em água, quando os tecidos animais são cozidos em água, podem ocorrer reduções das quantidades de taurina da proteína animal (Zanghini \& Biagi et al., 2005; Spitze et al., 2003; Case et al., 1998) mas, esta perda não ocorre quando os tecidos são assados (Spitze et al., 2003).

As rações empregadas na alimentação de cães não necessitam da adição de taurina, pois o cão tem a capacidade de produzir taurina usando outros aminoácidos, tornando-se assim um aminoácido não essencial para espécie, diferente do gato que necessita da suplementação de taurina. Problemas de carência ocorrem quando gatos são alimentados por longos períodos com rações para cães ou alimentos com carência do aminoácido.

A Nutrient Profiles for Cat Foods da AAFCO exige que os alimentos enlatados para gatos contenham um mínimo de $2.000 \mathrm{mg} / \mathrm{kg}$ e que os alimentos secos contenham um mínimo de $1.000 \mathrm{mg} / \mathrm{kg}$ de taurina, conseguindo assim atender as necessidades dos felinos (Case et al., 1998).

\section{Probióticos}

O conhecimento sobre os benefícios dos probióticos no organismo humano tem mais de 50 anos de história, descrito por Lilley \& Stillwell (1965) onde o termo probióticos foi utilizado para descrever substâncias que eram secretadas por microrganismos que por sua vez estimulavam o crescimento de outras. Fuller (1989) modificou este conceito, descrevendo os probióticos como um suplemento alimentar constituído por microrganismos vivos, capazes de beneficiar os hospedeiros através do equilíbrio da microbiota intestinal. Atualmente existe uma definição de probióticos que é utilizada pela Organização Mundial de Saúde e Organização de Agricultura e Alimentos, sendo a seguinte: "microrganismos vivos que quando administrados em quantidades adequadas, conferem benefícios à saúde dos hospedeiros" (JOINT FAO/WHO, 2002).

Os microrganismos desempenham diversas funções no organismo de humanos e animais, muitos dos quais ainda não foram descobertos, mas o que se sabe é que exercem desempenho na proteção do organismo contra infecções e outras doenças, pelo fato de bloquearem a colonização de microrganismos patógenos e estimularem as respostas imunológicas no local. Além disso, efetuam inúmeras atividades enzimáticas, contribuindo para o fornecimento de vitaminas e minerais (Oliveira \& Batista, 2003). O efeito protetor da microbiota intestinal tem sido relacionado com antagonismo bacteriano, interferência bacteriana, efeito barreira, resistência à colonização, ou exclusão competitiva. Os mecanismos que preserva o balanço entre os diversos microrganismos intestinais e impedem que uma determinada bactéria se torne dominante, também previne a invasão por bactérias exógenas (incluindo patogênicas) e o seu estabelecimento no ecossistema intestinal (Saad et al., 2011)

Likimani \& Sofos (1990) estudando a resistência de esporos de Bacillusglobigii em ração de cães com uma temperatura de extrusão de 100 a $140^{\circ} \mathrm{C}$ obteve efeito destrutivo, provocando a diminuição no número de esporos. Biourge et al. (1998) relatam que para não haver a destruição e diminuição da eficiência de um probiótico, o mesmo deve ser adicionado na ração após o processo de extrusão, não sofrendo assim a ação da temperatura.

Com o passar dos anos e a evolução da tecnologia em relação à inclusão de microrganismos nas rações extrusadas, a indústria tem produzido aditivos probióticos termo resistentes, compostos por bactérias vivas encapsuladas e resistentes ao processo de extrusão. Os microrganismos adicionados, além de ser resistente a temperatura também são liofilizados, ou seja, permanecem em estado latente até a ingestão, após encontrarem um ambiente favorável no intestino, voltam a sua forma vegetativa. Segundo Saad et al. (2011) os microrganismos utilizados como probióticos são 
usualmente componentes não patogênicos da microbiota normal, tais como as bactérias ácido láticas (principais gêneros: Lactococcus, Lactobacillus, Streptococcus e Enterococcus) e leveduras como Saccharomyces. Em estudos realizados com filhotes de cães com 10 semanas de idade e sem raça definida, não foram encontradas diferenças significativas da digestibilidade da matéria seca, matéria orgânica e carboidratos, na alimentação com ou sem a adição de probióticos (Biourge et al., 1998). Estudos realizados por Feliciano et al. (2009) demonstraram que a adição de probióticos na alimentação de cães não alterou a digestibilidade do alimento. $\mathrm{O}$ escore fecal foi alterado positivamente somente quando a alimentação dos cães foi substituída de Standard para Super Premium. Os dados apresentados acima demostram que devem ser realizados mais estudos para saber a influência dos probióticos sobre a qualidade de vida e a melhoria na digestibilidade nos animais de companhia.

\section{Prebióticos}

Os prebióticos são compostos não digeridos pelo trato gastrointestinal (TGI), mas seletivamente fermentados pelos microrganismos que habitam o TGI, podendo estar presentes nos ingredientes das dietas ou adicionados a elas por fontes exógenas concentradas (Gibson \& Roberfroid, 1995). As substâncias de efeitos prebióticos não devem ser metabolizadas ou absorvidas durante a passagem pelo TGI, devendo apenas ser um substrato para as bactérias intestinais benéficas, estimulando assim o crescimento bacteriano, alterando a microbiota intestinal de forma benéfica (Gibson \& Roberfroid, 1995).

Os prebióticos mais utilizados na nutrição humana e animal estão dentro da família dos oligossacarídeos, separados em: Frutoligossacaródeos (FOS), Manano-ligossacarídeos (MOS), Galactoligos-sacarídeos (GOS). Os FOS são atribuídos a diversos efeitos benéficos à saúde, como por exemplo: prevenção de cáries dentárias; redução dos níveis séricos de colesterol total e lipídeos; estímulo do crescimento de bifidobactérias no trato digestivo (Passos \& Park, 2003). São oligossacarídeos de ocorrência natural em produtos de origem vegetal (Hartemink et al., 1997) podendo ser encontrados em mais de 36 mil plantas diferentes (Roberfroid, 1993). As maiores quantidades e as plantas mais conhecidas são: alcachofras, aspargos, beterraba, chicória, banana, alho, cebola, trigo, tomate (Spiegel et al., 1994; Yun, 1996). Estes oligossacarídeos que não são digeridos no intestino delgado, alcançam o intestino grosso e são fermentados por bactérias anaeróbicas da flora intestinal, produzindo grandes quantidades de $\mathrm{AGV}$, além de $\mathrm{CO} 2$, amônia e H2. Como consequência, o pH no lume do intestino grosso torna-se bastante ácido (Otero, 2003 apud Saad et al., 2011).

As bactérias benéficas, como as Bifidobacterias e Lactobacillus são resistentes ao meio ácido, ao contrário das bactérias prejudiciais, como o Clostridium, E. Coli, Listéria, Shigella e Salmonella (Saad et al., 2011), tornado assim o meio seletivo ao desenvolvimento de bactérias benéficas. Em revisões realizadas por Saad et al. (2011) vários estudos são citados demonstrando diminuição significativa de bactérias patogênicas e o aumento de bactérias benéficas em cães suplementados com $1 \%$ de FOS isolado da raíz da chicória, e outros com a ingestão de capsulas contendo 2 gramas de FOS.

Os MOS e GOS também podem ser utilizados como prebióticos na nutrição de cães e gatos. Os MOS são derivados das paredes de leveduras. Segundo Saad et al. (2011) os MOS apresentam a capacidade de modular o sistema imunológico e a microflora intestinal, ligam-se a uma ampla variedade de micotoxinas, também bloqueiam a aderência de bactérias patogênicas, ocupando o sítio aonde elas poderiam se ligar na mucosa intestinal. Estudos realizados por Domingues et al (2014) demonstraram que a adição de $0,2 \%$ de MOS na dieta total de cães não altera a digestibilidade e a consistência fecal, mas reduz o odor da fezes.

Em rações secas, com incorporação de parede celular de levedura na dieta de cães não houve alteração na população microbiana das fezes, mas seus efeitos prebióticos foram comprovados, pois modificou a atividade metabólica dos microrganismos, aumentando a concentração de ácido butírico e reduzindo as de histamina, tiramina, triptamina, feniletilamina e também houve uma imuno estimulação nos cães (Gomes, 2009).

As citações demonstram que a adição de prebióticos nas rações para animais de companhia necessitam de mais estudos, com diferentes fontes e quantidades de substâncias prebióticas, conseguindo assim comprovar todos os benefícios no organismo de cães e gatos. 


\section{Antioxidantes}

Segundo o decreto $\mathrm{n}^{\circ} 55871$ da ANVISA de Janeiro de 1965, antioxidante é uma substância que retarda o aparecimento de alteração oxidativas nos alimentos. Estes aditivos podem ser sintéticos, muito utilizado na indústria alimentício, ou natural, fazendo parte assim da constituição da matéria prima empregada na produção e industrialização dos alimentos.

De acordo com a FDA (2014) que trata da regulamentação dos aditivos, os antioxidantes são substâncias utilizadas para preservar alimentos através do retardamento da deterioração, rancidez e descoloração decorrente da oxidação.

A deterioração dos alimentos é feita pelo ataque de $\mathrm{O}_{2}$, formando peróxidos, ou seja, os radicais livres, que são os responsáveis pelo mau odor e a rancificação dos alimentos, podendo causar doenças aos animais. Os compostos que agem contra os radicais livres (espécies reativas do oxigênio ou ROS) são os antioxidantes, podendo ser sintéticos ou naturais (Saad et al., 2011). Além de proteger os alimentos da deterioração, os antioxidantes protegem as células dos animais contra o ataque dos radicais livres, além da prevenir o envelhecimento celular.

A formação dos ROS nos animais ocorre durante os processos oxidativos biológicos, formados no sistema biológico, gerados a partir de compostos endógenos e exógenos no organismo. Dentro deste processo pode-se destacar a fosforilação oxidativa, responsável pela geração de ATP no organismo (Renz \& González, 2003).

Os antioxidantes são um conjunto heterogêneo de substâncias formadas por vitaminas, minerais, pigmentos naturais e outros compostos vegetais, e ainda enzimas, que bloqueiam os efeitos danosos dos radicais livres (Food Ingredients Brasil, 2009).

\section{Vitaminas}

A vitamina A não é encontrada nas plantas, mas contém uma provitamina chamada de caroteno. $\mathrm{O}$ betacaroteno tem a maior atividade da vitamina A quando comparada a outros carotenoides, mas só tem a metade da potência da vitamina pura (Gross et al., 2000). Também pode ser encontrada no fígado e nos óleos de fígado de peixe, como também no peixe e nas gemas dos ovos (Case et al., 1998; Gross et al., 2000).
Os mamíferos não estão capacitados bioquimicamente para a biossíntese de carotenoides, mas podem acumular e converter precursores que obtém da dieta, podendo assim converter o betacaroteno em vitamina A (Fontana et al., 2000). Diferentes dos cães, os gatos não tem a enzima intestinal que é capaz de converter o betacaroteno em vitamina A ativa, desta forma é necessária à suplementação de vitamina A préformada para que não ocorra déficit no organismo dos felinos (Case et al., 1998).

A vitamina A é armazenada no fígado na forma de palmitato e apresentada no soro na forma de retinol, a principal atuação deste nutriente é na visão, mitose e diferenciação celular (Greghi et al., 2010). Segundo Gross et al. (2000) a vitamina A é necessária para o crescimento ósseo, reprodução, desenvolvimento dentário e manutenção do tecido epitelial. A falta resulta na disfunção do tecido epitelial, aumentando a susceptibilidade de infecções. A espermatogênese do macho e o ciclo estral nas fêmeas também são dependentes da vitamina $\mathrm{A}$.

A vitamina $\mathrm{C}$ pode ser sintetizada pela maioria dos seres vivos, inclusive pelos cães e gatos, desta forma é improvável que ocorra a carência do organismo dos animais pet (Case et al., 1998). Nas rações para cães e gatos, a finalidade é atuar prevenindo a oxidação dos ácidos graxos, agindo na conservação e na manutenção da qualidade das rações. Todos os cães e gatos conseguem sintetizar no organismo quantidades adequadas de vitamina $\mathrm{C}$, pois o ácido ascórbico é produzido no fígado a partir da glicose, através da via metabólica do glucuronato (Case et al., 1998). A vitamina C exerce grandes benefícios no organismo dos cães e gatos pela hidroxilação dos aminoácidos prolina e lisina, no processo de formação do colágeno, atuando sobre o tecido conjuntivo (Case et al., 1998). Além disso, é um removedor dos radicais superóxidos hidroxila e oxigênio e preserva os níveis de vitamina $\mathrm{E}$ e beta-caroteno durante o estresse oxidativo (Batlouni, 1997)

Fisiologicamente os cães e gatos não necessitam da adição de vitamina $E$ em sua alimentação, devido à síntese pelo organismo, podendo ser adicionada apenas com fins de preservar a qualidade do alimento. Mesmo assim, devido à falta de informações, alguns proprietários de cães e gatos realizam a suplementação das dietas com a adição de uma gama de vitaminas, incluindo o ácido ascórbico, 
que segundo Case et al. (1998) quando em excesso é excretado pela urina e forma de oxalato, e o aumento de sua concentração contribui para a formação de cálculos no aparelho urinário. A vitamina $\mathrm{E}$, tem a sua forma ativa chamada de alfa-tocoferol, é um antioxidante lipossolúvel predominante nos tecidos. Atua capturando os radicais peroxila e interrompendo a cadeia de peroxidação lipídica. É essencial para a proteção das lipoproteínas circulantes e ao funcionamento adequado das membranas celulares (Batlouni, 1997). Segundo SAAD et al. (2011) a vitamina $\mathrm{E}$ age como um antioxidante biológico dentro dos fosfolipídeos de membrana, protegendo as células contra a oxidação. Para conservar a eficácia da vitamina $\mathrm{E}$ é necessária a presença da vitamina $\mathrm{C}$, pois preserva os níveis de vitamina $\mathrm{E}$, beta-caroteno, antioxidantes endógenos na LDL durante o estresse oxidativo.

A vitamina $\mathrm{E}$ funciona como um conservante das rações, protegendo os AGPI (ácidos graxos poliinsaturados) dos danos oxidativos (Case et al., 1998), também está relacionada ao selênio, pois ele é um cofator da glutationaperoxidase, que reduz os peróxidos formados durante o processo de oxidação dos ácidos graxos. A inativação desses peróxidos pela glutationaperoxidase protege a membrana celular de um dano oxidativo adicional (Case et al., 1998).

\section{Zeólitas e extrato de yucca}

A aproximação dos cães e gatos com o homem provocou maior contato do proprietário com as fezes dos animais, gerando diversos desconfortos decorrentes do odor. Para amenizar este problema, os donos dos animais procuram fornecer rações secas que resultam em fezes mais firmes e com menos odor. A redução do odor das fezes e a melhora da digestibilidade dos alimentos podem ser obtidas através de dietas com ingredientes de alta digestibilidade e boa qualidade (Maia et al., 2010). Para alcançar estes objetivos mais facilmente, as rações devem ser enriquecidas com extrato de Yucca schindigera, pois inibe a urease pela fração de saponinas do extrato, diminuindo assim a excreção de amônia nas fezes, que é o responsável pelo odor das mesmas (Preston et al., 1987) também é considerada uma ótima fonte de fibras, auxiliando assim no transito intestinal (Mcfarlane et al., 1988). A Yucca Schindigera é uma planta que cresce nos desertos, possui porte médio e produz vários galhos maduros em um período de 4 a 5 anos. Os galhos maduros são colhidos e posteriormente passam por um processamento. Este processamento consiste na moagem e secagem, resultando em um pó desidratado chamado de extrato, utilizado nas rações dos animais.

Outro composto que pode ser utilizando são as zeólitas na alimentação dos animais, pois tem a capacidade de absorver gases, vapores e água (Pond et al., 1995). Dentre as zeólitas, o mais utilizado na nutrição animal são os aluminossilicatos hidratados. Segundo a definição clássica, o termo zeólitas abrange somente aluminossilicatos cristalinos hidratados de estrutura aberta, constituída por tetraedros de $\mathrm{SiO}_{4}$ e $\mathrm{AlO}_{4}$, ligados entre si pelos átomos de oxigênio. Encontra-se em rochas ígneas básicas e disseminadas em arenitos (Bvreck, 1974). Estudos realizados por Maia et al. (2010) demonstraram que dietas contendo $0,75 \%$ e $1 \%$ de zeólitas da dieta total de cães, fizeram com que ocorresse a diminuição no odor das fezes (Tabela 1). Os mesmos estudos comprovam que a adição de $0,75 \%$ e $1 \%$ de zeólitas da deita total de cães fez com que as fezes ficassem mais firmes e de formato mais homogêneo melhorando assim o escore fecal (Tabela 2).

Tabela 1. Avaliação do odor das fezes de cães alimentados com rações contendo Yucca Schindigera ou zeólitas

\begin{tabular}{lc}
\hline Dieta & Média \\
\hline Controle & $5,00^{\mathrm{a}}$ \\
125 ppm Yucca Schindigera & $5,04^{\mathrm{a}}$ \\
250 ppm Yucca Schindigera & $5,60^{\mathrm{a}}$ \\
375 ppm Yucca Schindigera & $5,64^{\mathrm{a}}$ \\
$0,50 \%$ Zeólitas & $5,77^{\mathrm{a}}$ \\
$0,75 \%$ Zeólitas & $6,55^{\mathrm{b}}$ \\
$1,00 \%$ Zeólitas & $5,97^{\mathrm{b}}$ \\
$\mathrm{CV}(\%)$ & 15,54 \\
\hline
\end{tabular}

Médias seguidas por letras distintas diferem pelo teste SNK, a $5 \%$ de significância. CV $(\%)=$ Coeficiente de variação.

Os valores atribuídos às amostras seguiram uma escala de 0 a 10 , na qual os valores de 0 a 4 representavam classificações de odor mais forte que o padrão, o valor de 5 odor igual ao padrão e acima de 5 o odor era menor que o padrão, seno que a escala de odor vai de 0 a 10 . 
Estudos realizados por Maia et al. (2010) demonstraram que a inclusão de Yucca schidigera (125 a 375 ppm) de zeólitas $(0,5$ a $1,0 \%)$ não influencia a digestibilidade do alimento, o que indica que esses aditivos não alteram a digestibilidade, sendo que estas quantidades são adequadas para a inclusão na alimentação de cães.

Tabela 2. Escore fecal médio do material coletado, com base na consistência e no aspecto

\begin{tabular}{lc}
\hline Dieta & Consistência fecal \\
\hline Controle & $2,83^{\mathrm{e}}$ \\
125 ppm Yucca Schindigera & $3,16^{\mathrm{d}}$ \\
250 ppm Yucca Schindigera & $3,16^{\mathrm{d}}$ \\
375 ppm Yucca Schindigera & $3,43^{\mathrm{c}}$ \\
$0,50 \%$ Zeólitas & $3,63^{\mathrm{b}}$ \\
$0,75 \%$ Zeólitas & $3,86^{\mathrm{a}}$ \\
$1,00 \%$ Zeólitas & $3,93^{\mathrm{a}}$ \\
$\mathrm{CV}(\%)$ & 15,54 \\
\hline
\end{tabular}

Médias seguidas por letras distintas diferem pelo teste SNK a $5 \%$ de significância. CV $(\%)=$ coeficiente de variação. $\mathrm{O}$ escore fecal foi avaliado de 1 a 5 , em que 1 = fezes líquidas (diarreia); 2 = fezes macias sem forma definida; 3 = fezes macias, bem formadas $\mathrm{e}$ úmidas; 4 = fezes duras, secas, firmes e bem formadas; 5 = fezes muito duras e ressecadas, considerando ideal valor entre 3 e 4 .

\section{Polifenóis}

Os polifenóis são antioxidantes muito potentes que se encontram em diversos alimentos de origem vegetal, tais como: maçã, uva, cebola, repolho, brócolis, chicória, aipo, chá e vinho tinto, mas geralmente são extraídos da uva e do chá mate verde. Depois de absorvidos são metabolizados no fígado e secretados na bile, urina e saliva (Saad et al., 2011). O principal papel dos polifenóis é o seu impacto sobre os radicais livres, limitando os efeitos nocivos do estresse oxidativo. Adicionar polifenóis do chá verde na dieta pode melhorar a higiene oral, pois inibe o crescimento das bactérias da placa dental, que causam a doença periodontal, muito comum em animais idosos (Royal Canin, 2013).

Observou-se também um efeito positivo dos flavonóides, que fazem parte de uma categoria especial de polifenóis sobre doenças renais e cardíacas. Eles estimulam a produção de óxido nítrico, relaxando as fibras musculares lisas dos vasos sanguíneos. A administração diária do flavonóides é associada à queda de pressão arterial (Royal Canin, 2013). Os polifenóis e/ou flavonoides podem entrar como aditivos nas rações terapêuticas para cães e gatos, sendo utilizados para tratar ou prevenir problemas relacionados à pressão arterial elevada e às placas bacterianas em animais mais idosos.

\section{Glucosamina e condroitina}

A glucosamina é um açúcar aminomonossacarídeo sulfatado, constituinte das unidades dissacarídeas presentes nos proteoglicanos das cartilagens articulares (Saad et al., 2011).

A condoroitina constitui-se de uma molécula classificada como mucopolissacarídeo, grupo que atualmente é designado por glucosaminoglucanas (Saad et al., 2011), são macromoléculoas formadas por açúcares e proteínas.

No tecido cartilaginoso de diversas espécies, inclusive no homem, a presença de algum tipo de condoroitina é bastante evidente. As condoroitinas 4 e 6-sulfato despertam grande interesse, por serem estruturas hidrolisáveis e fornecedoras dos monômeros para a síntese de demais mucopolissacarídeos, todos de grande importância para tecidos de sustentação e nas doenças articulares e do tecido ósseo (Saad et al., 2011). Trabalhos executados in vitro demonstram que a falta de glucosamina pode alterar o metabolismo dos condrócitos, sendo esta a razão de sua utilização no tratamento de osteoratrite (Saad et al., 2011). A glucosamina está envolvida na formação da cartilagem nas articulações e também contribui para a elasticidade. A sua principal função é estimular a formação de nova cartilagem, atuando juntamente com a condoroitina que inibe o efeito das enzimas que causam a destruição permanente da cartilagem (Royal Canin, 2013).

As doenças articulares vão surgindo com o decorrer da vida dos cães, e a predominância de doenças nas articulações deve-se muito a raça do animal, sendo que as de porte grande apresentam maior predisposição a doenças articulares e do tecido ósseo.

A adição de glucosamina e condroitina nas dietas faz com que ocorra a manutenção da saúde das articulações e dos ossos, diminuindo a incidência e prevenindo o desenvolvimento de artroses, osteoartrite e doenças articulares. A adição destes nutrientes é indicada para cães idosos, obesos, atletas, cães guia ou animais 
susceptíveis. Desta forma, este aditivo na alimentação faz com que o organismo contenha a inevitável degeneração das cartilagens.

Tanto a condroitina como a glucosamina podem ser extraídos das cartilagens de diversas espécies de animais, incluindo peixes, moluscos, suínos e aves. Na forma comercial, a condroitina é fornecida como sulfato de condroitina.

\section{Glm (green-lipped mussels)}

Conhecido como extrato do Mexilhão de Lábios Verdes (GLM) possui propriedades interessantes, que atuam na prevenção e tratamento da osteoartrite. Vários estudos demonstram a redução da dor e a melhoria da mobilidade articular de pacientes caninos quando essa substância é administrada. O GLM ajuda a conter a inflamação, preservar a integridade da cartilagem e combater as lesões oxidativas (Royal Canin, 2013).

Os mexilhões agem como um filtro da água do mar, retendo vários nutrientes, como resultado o GLM contém uma grande quantidade de substâncias potencialmente ativas que combatem a inflamação da artrite: ácidos graxo ômega 3, condroitina, glutamina, vitaminas $\mathrm{E}$ e $\mathrm{C}$ e elementos-traço (zinco, cobre, manganês). O pó de GLM é um extrato da carne do mexilhão de lábios verdes (Royal Canin, 2013).

Um grande problema é que o processamento térmico dos GLM pode destruir a sua capacidade terapêutica, desta forma o processamento do GLM e a incorporação em produtos alimentares requerem técnicas especiais de processamento, pois se não houver cuidados pode ocorrer à perda da eficácia do produto final, devendo haver processamento com baixa temperatura (Bierer \& Bui, 2002).

Estudos realizados por Bierer \& Bui (2002) demonstraram que o GLM em pó é eficaz na redução dos sinais de artrose em cães, tanto quando incorporados na ração ou aspergidos sobre a dieta. Os escores totais da artrite nas pontuações de dor e inchaço foram reduzidos significativamente após 6 semanas de suplementação com o GLM.

Para a adição nas rações secas para cães $\mathrm{e}$ gatos deve-se ter consciência da inativação e a destruição de diversas propriedades do extrato pelo calor, devendo ser realizadas formas alternativas que façam com que o calor não prejudique a função terapêutica do aditivo.

\section{Minerais quelatados}

Os fatores que mais influenciam a absorção de um mineral pelo organismo é a sua forma química (Miller, 1975 apud Saad et al., 2011). Também se sabe que os micros elementos fornecidos na forma inorgânica podem ter sua biodisponibilidade influenciada por outros nutrientes da dieta e a questão fisiológica do próprio animal (Lowe, 1993 apud Saad et al., 2011). Segundo Vandergrift (1993) apud Saad et al. (2011) uma definição técnica de quelatos seria a de um mineral da primeira série de transição da cadeia periódica $(\mathrm{Cr}, \mathrm{Mn}, \mathrm{Co}, \mathrm{Ni}, \mathrm{Cu}, \mathrm{Zn})$ que se liga a aminoácidos via ligação coordenada covalente, formando uma substância estável e eletricamente neutra. Neste estado de quelato, o metal é quimicamente inerte, não sofrendo influência de outros componentes das dietas, como as fibras e gorduras (Saad et al., 2011). Nas rações secas para cães e gatos, os minerais são adicionados em sua grande maioria na forma inorgânica. Mas, no trato gastrointestinal a maioria dos minerais para serem absorvidos necessita fazer ligação iônica com aminoácidos que se encontram no estomago e no intestino (Saad et al., 2011). Quando este processo ocorre livre no organismo, vários fatores podem interferir. Um exemplo é o de que diferentes minerais necessitam se ligar a um mesmo aminoácido para serem absorvidos, isso ocorre no caso do zinco e do cobalto que necessitam se ligar a metionina para serem absorvidos (Saad et al., 2011).

A (Tabela 3) apresenta os resultados de um estudo realizado por FRANÇA et al (2008) com 24 gatos adultos, suplementados com três fontes diferentes de zinco, onde pode-se observar que os animais que receberam a suplementação com a fonte quelatada obtiveram maior concentração de zinco na pele e no pêlo.

Tabela 3. Valores médios e seus respectivos errospadrão da concentração de zinco na pele e no pelo de gatos adultos, em ppm, em função dos tratamentos estudados.

\begin{tabular}{lcc}
\hline \multirow{2}{*}{ Tratamentos } & \multicolumn{2}{c}{ Zinco $(\mathrm{ppm})$} \\
\cline { 2 - 3 } & Pele & Pêlo \\
\hline Quelato de Zinco & $47,06(2,28)^{\mathrm{a}}$ & $278,5(20,4)^{\mathrm{a}}$ \\
Sulfato de Zinco & $37,46(2,28)^{\mathrm{b}}$ & $213,3(20,4)^{\mathrm{ab}}$ \\
Óxido de Zinco & $46,07(2,28)^{\mathrm{ab}}$ & $187,0(22,4)^{\mathrm{b}}$ \\
Controle & $40,11(2,28)^{\mathrm{b}}$ & $186,8(20,4)^{\mathrm{b}}$ \\
CV $(\%)$ & 10,71 & 22,98 \\
\hline
\end{tabular}

${ }^{\mathrm{a} b}$ Médias seguidas de mesma letra, na coluna, não diferem entre si, pelo teste de Tukey a um nível nominal de significância de $5 \%$. 
Os quelatos visam melhorar a absorção dos minerais pelo organismo, pois não necessitam formar complexo dentro do sistema gastrointestinal, desta forma quando ingeridos na forma quelatada são prontamente absorvidos, ocorrendo maior aproveitamento pelo animal, tendo assim maior biodisponibilidade. Os minerais quelatados podem ser definidos como minerais que estão quimicamente ligados a aminoácidos, formando uma estrutura em anéis (Paula, 2014). Estes anéis heterocíclicos formados modificam as características físicas e químicas dos grupos coordenados, protegendo-os da influência de fatores externos, tornando-os resistentes a dissociação, ficando estáveis quimicamente facilitando assim a sua absorção (Malleto, 1984 apud, Saad (2011).

Estudos realizados por Kuhlman \& Rompala (1998) demonstraram que cadelas Beagle suplementadas dieteticamente com $\mathrm{Zn}, \mathrm{Cu}$ e $\mathrm{Mn}$ na forma de quelatos, obtiveram melhora no desempenho reprodutivo, obtendo maior número de filhotes por gestação.

\section{Ácidos graxos essenciais}

Os ácidos graxos podem ser obtidos pelas dietas na forma natural, fazendo parte assim da constituição do alimento, ou na forma de aditivos, principalmente utilizados em rações Super Premium com funções terapêuticas, utilizados para prevenir ou tratar algum tipo de enfermidade que possa estar ligado à carência destes lipídeos.

Segundo Bauer (2008) a natureza essencial de um ácido graxo é principalmente devido à incapacidade do animal de sintetizá-lo em quantidades suficientes para satisfazer as suas necessidades metabólicas.

Os ácidos graxos essenciais para o metabolismo são: linoleico; araquidônico (ômega 6) e possivelmente o ácido alfa linolênico (ômega 3). Assim como a maioria dos animais, os cães conseguem satisfazer as suas necessidades de ácidos graxos (n-6) mediante a uma fonte dietética adequada de ácido linoleico (Case et al., 1998).

A delta-6-dessaturase e a delta-5-dessaturase são duas enzimas essenciais na via metabólica para a síntese de ácido gama linolênico e araquidônico a partir do ácido linoleico. Diferente do cão, o gato apresenta em seu organismo carência de delta-6- dessaturase e baixa atividade da delta-5-dessaturase no fígado, sendo incapaz de sintetizar ácido araquidônico a partir do linoleico (Case et al., 1998).

Estudo realizado por Mcdonald (1984) apud Bauer (2008) descobriu que gatos machos alimentados com uma dieta deficiente em ácido linoleico resultam em degeneração tubular dos testículos. No caso de fêmeas prenhas, estas não conseguiam manter a gestação até o final quando alimentadas com dietas ausentes em ácido linoleico. Segundo Case et al. (1998) quando na dieta de gatos encontrava-se presente o ácido linoleico e não o araquidônico, as gatas não conseguiam parir gatinho vivos, os gatos sofriam uma agregação das plaquetas e trombocitopenia, que é caracterizado por diminuição no número de plaquetas circulantes.

Gatos com deficiência de ácido araquidônico apresentam um ligeiro aumento do conteúdo lipídico hepático e uma ligeira mineralização dos rins. Outros sintomas foram notados, tais como: estado deficiente da capa pilosa; atraso no crescimento; deterioração da cicatrização das feridas; desenvolvimento de lesões cutâneas (Case et al., 1998). De acordo com Case et al. (1998) apenas o ácido linoleico é necessário na dieta dos cães, mas a dieta do gato deve conter o linoleico e o araquidônico. Segundo esse mesmo autor o ácido linoleico é essencial para a manutenção da saúde da pele e a regulação à permeabilidade da água. Para gatos o ácido araquidônico participa da função reprodutora e agregação das plaquetas.

Segundo Royal Canin (2013) os óleos vegetais são geralmente ricos em ácidos graxos ômega 6. Algumas gorduras insaturadas de origem animal, especialmente de suínos e aves, também podem conter grandes quantidades de ácido linoléico (mais de $20 \%$ no caso das aves). A gordura da carne bovina (banha, manteiga), por outro lado, contém muito pouco ácido linoléico. De acordo com a mesma fonte, alguns óleos vegetais (linhaça, soja, colza), contêm quantidades expressivas de ácido alfa linolênico (ALA).

\section{Conclusões}

Os aditivos são muito importantes para a alimentação de cães e gatos, devido ao fato dos donos de animais de estimação tornar-se responsáveis pelo total fornecimento da alimentação. Desta forma as indústrias vêm produzindo alimentos que atendam às necessidades nutricionais e melhorem a qualidade 
de vida dos animais pet. Devem sempre ser levadas em consideração as exigências de ambas as espécies e as particularidades de cada uma. Quando adicionados em níveis adequados tornase uma importante ferramenta para a melhoria da qualidade da dieta, aprimorando a saúde dos animais de estimação.

Devem ser realizados mais estudos com maior tempo de duração e níveis diferentes de adição de Extrato de Yucca, Zeólitas, Probióticos e Prebióticos, com a finalidade de obter mais resultados que comprovem a eficiências destes aditivos na alimentação de cães e gatos.

\section{Referências Bibliográficas}

ABINPET. (2013). Dados referentes ao mercado pet food em (2013). Disponível " $<$ http://abinpet.org.br/imprensa/noticias/abin pet-divulgados-mercado-pet-2013/>" Acesso:05/06/2015.

ANVISA. (1965.). Decreto $\mathrm{N}^{\circ} 55.871$, de 26 de março de 1965. D.O.U. - Diário Oficial da União; Poder Executivo, de 09 de abril.

Batlouni, M. (1997). Hipótese oxidativa da aterosclerose e emprego dos antioxidantes na doença arterial coronária. Arquivo Brasileiro de Cardiologia, 68:1.

Bauer, J. J. E. (2008). Essential fatty acid metabolism in dog and cats. College of Veterinary Medicine, Texas A \& M University, College Station, TX 77843-4474 USA. Revista Brasileira de Zootecnia, 37.

Bierer, L. T. \& Bui, M. L. (2002). Improvement of arthritic signs in dogs fed Green-Lipped Mussel (Perna caniculus). The Journal of Nutrition, 132:1434S-1636S.

Biourge, V.; Vallet, C.; Levesque, A.; Sergheraerth, R.; Chevalier, S. \& Roberton, L.J. (1998). The use of probiotics in the diet of dogs. The Journal of Nutrition, 128:12.

Bvreck, D. W. (1974). Zeolite Molecular Sieves, Wiley, Nova Iorque.

Case, P. M.; Carey, P. D. \& Hirakawa, A. D. (1998). Nutrição canina e felina: manual para profissionais. Ed. Hancourt Brace. p.423.

Domingues, P. L.; Silva, R. L.; Shen, A. N.; Félix, P. A.; Oliveira, G. S. \& Maiorka, A. (2014). Suplementação de mananoligossacarídeos reduz o odor fecal sem alterar a digestibilidade. VI Congresso internacional e
XIII Simpósio sobre nutrição de animais de estimação. CBNA - Valinhos, SP - Trabalhos Científicos.

FDA. Food Additives. Department of Health and Human Service. Code of Federal Regulations. Title 21, vol.3, revised as of April 1, (2014).

Feliciano, M. A. R.; Saad, B. O. M. F.; Logato, P. V. R.; Aquino, A. A.; José, V. A. \& Roque, N. C. (2009). Efeito de probióticos sobre a digestibilidade, escore fecal e características hematológicas em cães. Arquivo Brasileiro de Medicina Veterinária e Zootecnia, 61:6.

Fontana, D.J.; Mendes, V.A.; Persike, S.D.; Paracetta, F.L. \& Passos, M. Carotenoides. Revista de Biotecnologia. Disponível: <http://www.biotecnologia.com.br/edicoes/ed 13.php> Acesso: 06/09/2014, ed.13, março/abril de 2000.

Food Ingredients Brasil. (2009). Os antioxidantes. Revista FIB, Nº. 6, Edição de Janeiro.

França, J.; Saad, B. O. M. F.; Saad, P. E. C.; Silva, C. R. \& Reis, S. J. (2011). Avaliação de ingredientes convencionais e alternativos em ração de cães e gatos. Revista Brasileira de Zootecnia, 40:222-231.

França, J.; Saad, B. O. M. F.; Silva, W. J. J.; Numariji, N. M.; Pinto, F. B. A. \& Chizzotti, F.A. (2008). Fontes suplementares de zinco para gatos adultos. Revista Brasileira de Saúde e Produção Animal, 9:449-459.

Fuller, R. (1989). Probiotics in man and animals. Journal Applied and Bacteriology, 66:365378.

Gibson, G. R. \& Roberfroid, M. B. (1995). Dietary modulation of the human colonic macrobiotic: Introducing the concept of prebiotics. Journal of Nutrition, 125:1401-12.

Gomes, S. O. M. (2009). Efeito da adição de parede celular de levedura sobre a digestibilidade, microbiota, ácidos graxos de cadeia curta e aminas fecais, e parâmetros hematológicos e imunológicos em cães. Dissertação (mestrado) - UNESP Jaboticabal.

Greghi, F. G. \& Chanquetti, S. A. (2010). Dermatose responsiva à vitamina $\mathrm{A}$ em cães: Relato de caso. Sistema Anhanguera de Revistas eletrônicas, 14, $\mathrm{n}^{\circ} 2$.

Gross, K. L; Wedekind, K. L.; Cowell, C. C.; Schoenherr, W. D.; Jewel, D. E.; Zicker, S. 
C.; Debrakeller, J. \& Frey, R.A. (2000). Small animal clinical nutrition. Nutrients $4^{\text {th }}$, ed., p.66-80. Marceline, MO: Walsworth Publishing for Mark Morris Institute.

Hartemink, R.; Vanlaere, K .M. J. \& Rombouts, F. M. (1997). Growth of enterobacteria on fructo-oligosaccharides. Journal of Applied Microbiology, 383:367-374.

Hora, A. S. \& Hagiwara, M. K. (2010). A importância dos aminoácidos na nutrição dos gatos domésticos. Clínica veterinária, 15:3042.

Hungenholtz, J. \& Smid, E. J. (2002). Nutraceutical production with food-grade microorganisms. Current Opinion in Biotechnology, 13:497-507.

JOINT WHO/FAO/OIE. (2003). Food and Agricultural Organization/World Health Organization Background document for the Joint WHO/FAO/OIE expert. In: Workshop on nonhuman antimicrobials usage and antimicrobials resistance scientific assessment. Geneva, Switzerland, December $1-5,117 \mathrm{p}$.

Kruger, C. L. \& Mann, S. W. (2003). Safety evaluation of functional ingredients. Food and Chemical Toxicology, 41:793-805.

Kuhlman, G. \& Rompala, R. E. 1998. The Influence of Dietary Sources of Zinc, Copper and Manganese on Canine Reproductive Performance and Hair Mineral Content. The Journal of Nutrition, 128. n. 12.

Likimani, T.A. \& Sofos, J.N. 1990. Bacterial spore injury during extrusion cooking of corn/ soybean mixtures. International Journal of Food Microbiology, 11:243-250.

Lilley, D. M. \& Stillwell, R. H. (1965). Probiotics: growth promoting factors produced by microorganisms. Science, 147:747-748.

Maia, C. V. G.; Saad, B. O. N. F.; Roque, C. N.; França, J.; Lima, S. M. L. \& Aquino, A.A. (2010). Zeólitas E Yucca schindigera em ração para cães: palatabilidade, digestibilidade e redução de odores fecais. Revista Brasileira de Zootecnia, 39:2442-2446.

MAPA. (2004) Instrução normativa 13/2004. Disponível

“ $<$ http://sistemasweb.agricultura.gov.br/sisleg is/action/detalhaAto.do?method=visualizarAt
oPortalMapa \&chave $=133040692>"$ Acesso: 05/06/2015.

MAPA (2009). Instrução normativa 15/2009. Disponível

" $<$ http://sistemasweb.agricultura.gov.br/sisleg is/action/detalhaAto.do?method=visualizarAt oPortalMapa\&chave $=2113570100>$ Acesso: 05/06/2015.

Mcfarlane, J. M. \& Metheney, C. D. (1998). Effect of dietary Micro Aid on canine fecal odour. Porterville: Report, Distributors Processing Inc. p.67-71.

Oliveira, L.T. \& Batista, S. M. M. (2003). Atuação dos probióticos na resposta imunológica. Disponível em: <www.nutricaoempauta.com.br>, Acesso: 07/06/2015.

Passos, L. M. L. \& Park, K.Y. (2003). Frutooligos-sacarídeos: Implicações na saúde humana e utilização em alimentos. Ciência Rural, 33:385-390.

Paula, C. M. M. (2014). Minerais quelatados. Revista Veterinay \& Science, 101. ed.3. Julho.

Pond, W. G.; Church, C. D. \& Pond, K. R. (1995). Basic animal nutrition and feeding. 4.ed. New York: John Wiley, 615p.

Preston, R. L.; Bartle, S. J.; May, T. (1987). Influence of sarsaponin on growth, feed and nitrogen utilization in growing male rats fed diets with added urea or protein. Journal of Animal Science, 65:481-487.

Renz, V. S. \& González, D. H .F. 2003. Oxidação e antioxidantes. Seminário de bioquímica do tecido animal, no programa de Pós-Graduação em Ciências Veterinárias da UFRGS. Disponível em: < http://www.ufrgs.br/lacvet/restrito/pdf/oxid_a ntiox.pdf>, Acesso: 10/08/2015.

Roberfroid, M. (1993). Dietary fiber, inulin, and oligosaccharides: a review comparin their physiological effects. Crittical Review Food Science Nutrition, 33:103108.

Royal Canin. Nutrição e saúde animal. (2013). Disponível em: < http://www.royalcanin.com.br/>. Acesso: 06/07/2015.

Saad, B. O. M. F; Salgarello, M. R. \& Gurian, M. T. (2011). Recentes avanços na nutrição de cães e gatos. Disponível em: <http://wp.ufpel.edu.br/nutricaoanimal/files/2 
011/03/Avan\%C3\%A7os_caes_gatos.pdf>, Acesso: 07/062015.

Souza, R.V \& Silva, V. (2008). Embrapa caprinos e ovinos. Implicação do uso de aditivos na alimentação animal: resíduos e barreiras às exportações. Disponível: < http://www.alice.cnptia.embrapa.br/handle/do c/894679> Acesso: 04/09/2014.

Souza, P. H. M.; Souza Neto, M. H. \& Maia, G. A. (2003). Componentes funcionais nos alimentos. Boletim da SBCTA, 37:127-135.

Spiegel, J. E. Rose. R., Karabell, P., Frankos, V.H. \& Schmitt, D.F. (1994). Safety and benefits of frutooligosaccharides as food ingredients. Food Technology, 48:85-89.

Spitze, A. R.; Wong, D. L.; Rogers, Q. R. \& Fascetti, A. J. (2003). Taurine concentrations in animal feed ingredients cooking influences taurine content. Journal of Animal and Physiology Nutrition, 87:251-62.
Yun, J. W. (1996). Fructooligosaccharides Occurrence, preparation and applications. Enzymes and Microbial Technology, 19:107117.

Zanghini, G. \& Biagi, G. (2005). Nutritional peculiarities and diet palatability in the cat. Veterinary Research Communications, 29:3944.

Recebido em Dezembro 4, 2015

Aceito em Janeiro 8, 2016

License information: This is an open-access article distributed under the terms of the Creative Commons Attribution License, which permits unrestricted use, distribution, and reproduction in any medium, provided the original work is properly cited. 